\title{
BMJ Open Pre-existing type 2 diabetes and risk of lung cancer: a report from two prospective cohort studies of 133024 Chinese adults in urban Shanghai
}

\author{
Wan-Shui Yang, ${ }^{1,2,3}$ Yang Yang, ${ }^{1,2}$ Gong Yang, ${ }^{4}$ Wong-Ho Chow, ${ }^{5}$ Hong-Lan Li, ${ }^{1}$ \\ Yu-Tang Gao, ${ }^{1}$ Bu-Tian Ji, ${ }^{6}$ Nat Rothman, ${ }^{6}$ Wei Zheng, ${ }^{5}$ Xiao-Ou Shu, ${ }^{5}$ \\ Yong-Bing Xiang ${ }^{1,2}$
}

To cite: Yang W-S, Yang Y, Yang G, et al. Pre-existing type 2 diabetes and risk of lung cancer: a report from two prospective cohort studies of 133024 Chinese adults in urban Shanghai. BMJ Open 2014;4:e004875. doi:10.1136/bmjopen-2014004875

- Prepublication history for this paper is available online. To view these files please visit the journal online (http://dx.doi.org/10.1136/ bmjopen-2014-004875).

Received 17 January 2014 Revised 18 May 2014 Accepted 2 June 2014

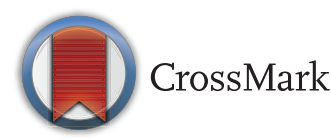

For numbered affiliations see end of article.

Correspondence to Professor Yong-Bing Xiang; ybxiang@shsci.org

\section{ABSTRACT}

Objectives: Observational studies of type 2 diabetes (T2D) and lung cancer risk are limited and controversial. We thus examined the association between T2D and risk of incident lung cancer using a cohort design.

Setting: Data from two ongoing population-based cohorts (the Shanghai Men's Health Study, SMHS, 2002-2006 and the Shanghai Women's Health Study, SWHS, 1996-2000) were used. Cox proportionalhazards regression models with T2D as a time-varying exposure were modelled to estimate $\mathrm{HRs}$ and $95 \% \mathrm{Cls}$.

Participants: The study population included 61491 male participants aged 40-74 years from SMHS and 74941 female participants aged $40-70$ years from SWHS.

Outcome measure: Lung cancer cases were identified through annual record linkage to the Shanghai Cancer Registry and Shanghai Municipal Registry of Vital Statistics, and were further verified through home visits and a review of medical charts by clinical and/or pathological experts. Outcome data until 31 December 2010 for men and women were used for the present analysis.

Results: After a median follow-up of 6.3 years for SMHS and 12.2 years for SWHS, incident lung cancer cases were detected in 492 men and 525 women. A null association between T2D and lung cancer risk was observed in men ( $\mathrm{HR}=0.87,95 \% \mathrm{Cl} 0.62$ to 1.21 ) and women ( $\mathrm{HR}=0.92,95 \% \mathrm{Cl} 0.69$ to 1.24 ) after adjustments for potential confounders. Similar results were observed among never smokers.

Conclusions: There is little evidence that pre-existing T2D may influence the incidence of lung cancer.

\section{INTRODUCTION}

Lung cancer is the most commonly diagnosed cancer as well as the leading cause of cancerrelated death globally and in China. ${ }^{1}$ The prevalence of diabetes has increased substantially in China, with the age-standardised rates

\section{Strengths and limitations of this study}

- We showed a null association between type 2 diabetes and risk of lung cancer in two population-based prospective cohorts with a large sample size and long-term follow-up.

- This null association remained after excluding lung cancer cases occurring within the first 3 years after diabetes onset and among never smokers.

- However, using self-reported diabetes as exposure, and the lack of pharmacological data on diabetes treatments including hypoglycaemic agent use and degree of glucose control do not allow firm conclusions.

from $2.4 \%$ in $1994^{2}$ to $9.7 \%$ in $2007-2008,^{3}$ which may parallel a marked lifestyle transition. ${ }^{4}$ Unlike the stable transition in most Western developed countries, these changes have occurred within a very short time in China.

Individuals with pre-existing type 2 diabetes (T2D) have been shown to be at risk for a number of cancers, including cancers of the liver ${ }^{5}{ }^{6}$ and pancreas. ${ }^{7}$ A link between T2D and lung cancer risk has also been suggested, but the evidence is limited and inconsistent. An inverse association was observed in four cohort studies, ${ }^{8-11}$ whereas an elevated risk of lung cancer was associated with T2D in five other cohort studies, particularly among women. ${ }^{12-16}$ Other studies, including eight cohort $^{17-24}$ and two casecontrol $^{25} 26$ studies, have reported a null association. These discrepancies could be due to a number of factors including insufficient statistical power (small sample size), different study designs and exposure ascertainments, and the lack of adjustments for important covariates such as smoking 
and body mass index (BMI). On the other hand, all previous studies only considered a single measurement of diabetes at the baseline survey, and cases of diabetes newly identified over follow-up periods were neglected, which may have resulted in some underestimation of the true associations. In addition, to the best of our knowledge, no prospective study until now has evaluated the effect of diabetes on lung cancer risk in mainland China.

To further clarify whether T2D influences the risk of lung cancer, we assessed the association of T2D with the risk of lung cancer by using data from the Shanghai Men's Health Study (SMHS) and the Shanghai Women's Health Study (SWHS), two ongoing large, populationbased prospective cohorts in urban Shanghai, China.

\section{METHODS}

Study population

The study population included 61491 male participants of SMHS and 74941 female participants of SWHS. Consent has been obtained from each participant after full explanation of the purpose and nature of all procedures used. Details of the study design, scientific rationale and baseline characteristics of the participants have been published previously. ${ }^{27}{ }^{28}$ Briefly, for SWHS, the recruitment for female residents of Shanghai aged 4070 years started in 1996 and was completed in 2000, with an overall participation rate of $92.7 \%$ (75 221/81 170). For SMHS, the recruitment for men aged 40-74 years with no history of cancer in Shanghai started in April 2002 and was completed in June 2006, with an overall participation rate of $74.1 \%$ (61 491/83 125). Participants were interviewed in person using a structured questionnaire to obtain information on demographic characteristics, lifestyle and dietary habits, medical history, family history of cancer and other exposures. Anthropometric measurements, including current weight, height and circumferences of the waist and hip, were also taken at baseline.

In this analysis, we excluded participants who had a history of cancer at enrolment (none for men and $\mathrm{n}=1598$ for women), were younger than 20 years on the day of diabetes diagnosis to reduce potential bias from including patients with type 1 diabetes $(n=3$ for men and 3 for women), died of cancers of unknown origin or without diagnosis date $(n=126$ for men and $n=114$ for women), had missing values for any of the covariates of interest ( $\mathrm{n}=1458$ for men and $\mathrm{n}=109$ for women), and were diagnosed with lung cancer before the diagnosis of diabetes $(\mathrm{n}=1$ for men and $\mathrm{n}=3$ for women). After exclusion, a total of 59910 men and 73114 women remained in the current analysis.

\section{Diabetes assessment}

In our analysis, diabetes cases were identified based completely on the self-reported data. Self-reported diabetes was recorded on the baseline questionnaires (2002-2006 for SMHS and 1996-2000 for SWHS), and updated in each of the subsequent follow-up questionnaires (2004-2008 for SMHS, and 2000-2002, 20022004 and 2004-2007 for SWHS). Participants were asked whether they had ever been diagnosed with diabetes mellitus by a physician (yes/no) and if yes, the age at which diagnosis was recorded. From the beginning with the 2004-2008 follow-up questionnaires for men and 2000-2002 follow-up questionnaires for women, and for all subsequent surveys, the question was modified and participants were additionally asked in what year and month and in which hospital their diabetes had been diagnosed since the most recent survey.

In the present study, a case of T2D was considered to be confirmed if the participant reported having been diagnosed with T2D and met at least one of the following self-reported items: (1) fasting plasma glucose concentration is greater than $7 \mathrm{mmol} / \mathrm{L}$ on two separate occasions, (2) plasma glucose concentration is greater than $11.1 \mathrm{mmol} / \mathrm{L}$ at $2 \mathrm{~h}$ for a $75 \mathrm{~g}$ oral glucose tolerance test and (3) the use of insulin or other hypoglycaemic agents. A validation study showed that the self-reported diabetes was in good agreement with the measurement of fasting plasma glucose concentration and medical treatment records in our cohorts (data were not shown).

\section{Follow-up and outcome ascertainment}

The participants were followed up with home visits every 2-3 years to update exposure information and to ascertain new diagnosis of cancers. For SMHS, the first follow-up interview was conducted from 2004 to 2008 with a response rate of $97.6 \%$. For SWHS, the first, second and third follow-ups were conducted from 20002002, 2002-2004 and 2004-2007 with corresponding response rates of $99.8 \%, 98.7 \%$ and $96.7 \%$, respectively.

The incident lung cancer cases were defined as a primary tumour with an International Classification of Diseases (ICD)-9 code 162, and were identified through annual record linkage to the Shanghai Cancer Registry and Shanghai Municipal Registry of Vital Statistics. All possible cancer cases were verified through home visits and a further review of medical charts by clinical and/or pathological experts. Outcome data until 31 December 2010 for men and women were used for the present analysis, with median follow-up periods of 6.3 and 12.2 years for SMHS and SWHS, respectively.

\section{Statistical analysis}

Cox proportional hazards regression models with age as a time scale were used to calculate age-adjusted and multivariate-adjusted HRs and 95\% CIs for the associations of T2D with the risk of incident lung cancer. T2D (yes/no) was modelled as a time-varying exposure in the current study, meaning that information on T2D reported in questionnaire $\mathrm{n}$ was used to prospectively categorise participants for the periods between completion of questionnaires $\mathrm{n}$ and $\mathrm{n}+1$, and that the risk person-years were allocated to the corresponding 
groups; the corresponding method has been described elsewhere in detail. ${ }^{5}$

Covariates were selected based on their potential to confound or modify the association between T2D and lung cancer. All covariates were modelled using baseline values. The covariates included in the multivariateadjusted models were age (less than 50, 50-60, more than 60 years), birth cohort (1920s, 1930s, 1940s, 1950s, 1960s), education (illiteracy or elementary school, middle school, high school, graduate school), income (low, low to middle, middle to high, high; see table 1), BMI (less than 18.5, 18.5-24, 24-28, more than 28, according to Chinese standards ${ }^{29}$ ), occupation (housewife (women only), manual, clerical and professional), smoking status (never smoking, ever smoking, current smoking, for men), smoking pack-years (0-10, 10-20, more than 20, for men), ever smoking (yes/no, for women), alcohol drinking (0, 0-1.5, more than 1.5, drink/day, for men), ever alcohol drinking (yes/no, for women), family history of cancer (yes/no), total energy intake ( $\mathrm{kcal} /$ day, quartiles), fruit intake ( $\mathrm{g} /$ day, quartiles), vegetable intake ( $\mathrm{g} /$ day, quartiles), total physical activity (PA; standard metabolic equivalents (METs) as MET-h/day in quartiles; 1 MET-h=15 min of moderate intensity activity), ${ }^{30}{ }^{31}$ history of hepatitis/chronic liver disease (yes/no), hormone replacement therapy (HRT; yes/no for women only), menopausal status (premenopausal/postmenopausal for women only).

We also tested for potential interactions of diabetes with age, income, education, occupation, family history of lung cancer, alcohol drinking, PA and smoking, by comparing the Cox models with and without the interaction terms using a likelihood ratio test. In the testing of the proportional hazard assumption by creating an interaction of diabetes and a logarithm of time in the model, we found no violation of proportionality.

To investigate the potential effect for over-detection bias (ie, the increased detection around the time of T2D diagnosis), age-adjusted incidence rates by different time intervals of follow-up (0-1, 1-3, more than 3 years) in the diabetes cohort and no diabetes cohort were calculated for lung cancer, which were directly standardised by the entire cohort population. To examine whether diabetes treatments affect the risk of lung cancer associated with T2D, a separate analysis that excluded treated diabetes was conducted.

All data analyses were performed with SAS V.9.2 (SAS Institute, Cary, North Carolina USA), and a two-sided $\mathrm{p}$ value of 0.05 was considered statistically significant if not specified.

\section{RESULTS}

\section{Results from SMHS and SWHS}

The distributions of selected baseline characteristics according to T2D are shown in table 1 . In this analysis, $7.7 \%$ (4599) of men and $8.6 \%$ (6291) of women reported having been diagnosed with T2D at baseline or during follow-up periods. Compared with men and women without diabetes, patients with T2D were older and had higher BMI, greater intake of total energy and vegetable, but less fruit consumption and alcohol drinking at baseline. In SWHS, less than $2.8 \%$ of the women reported ever smoking.

Until 31 December 2010, incident lung cancer cases weres detected in 492 men and 525 women. For men, the age-standardised incidence rates $(1 / 100000$ personyears) of lung cancer were 87.48, 20.73 and 161.92 for 0-1, 1-3 and more than 3 years, respectively, following the diabetes index date in the diabetes cohort; 112.97, 119.57 and 141.81 for $0-1,1-3$ and more than 3 years, respectively, since the baseline interview for the cohort without diabetes. For women, the age-standardised incidence rates $(1 / 100000$ person-years $)$ were $80.53,19.81$ and 72.85 for $0-1,1-3$ and more than 3 years, respectively, following the diabetes index date in the diabetes cohort; and 29.68, 41.43 and 69.46 for $0-1,1-3$ and more than 3 years, respectively, since the baseline interview for the non-diabetes cohort.

After adjustments for smoking, BMI, alcohol drinking and other factors, T2D was not associated with the risk of developing lung cancer either in men $(\mathrm{HR}=0.87,95 \%$ CI 0.62 to 1.21 ) or in women (HR=0.93, $95 \%$ CI 0.69 to 1.25; table 2). This null association remained when the analysis was restricted to never smokers (table 3) or after excluding lung cancer cases diagnosed within the first 3 years after diabetes diagnosis (table 2). Results from the subgroup analysis by waist-to-hip ratio (WHR), waist circumference, smoking and menopausal status (women) did not appreciably alter the main results (table 3). We did not observe effect modification by age, income, education, occupation, family history of lung cancer, alcohol drinking or PA. In addition, an additional analysis that excluded treated diabetes also showed a null association between untreated diabetes and lung cancer (data not shown).

\section{DISCUSSION}

No observational study, to the best of our knowledge, has investigated lung cancer risk in relation to T2D in mainland China until now. Findings from our population-based cohort study suggested that T2D is not associated with the risk of incident lung cancer among Chinese adults. This null association remained regardless of age, income, education, occupation, family history of lung cancer, alcohol drinking, PA, smoking status, menopausal status and WHR in stratified analysis.

Previous epidemiological studies on T2D and lung cancer yielded conflicting results, varying from a positive, ${ }^{1632}$ null $^{17} 19-222433-35$ to an inverse ${ }^{9-11}$ association. Differing study design, sample size or follow-up time and covariate adjustments may, in part, explain this inconsistency. A comparative study ${ }^{8}$ and three cohort studies ${ }^{9-11}$ without adjustments for smoking concluded an inverse association; two cohort studies that reported a positive 
Table 1 Characteristics of study participants according to type 2 diabetes status in the Shanghai Men's Health Study (20022010) and the Shanghai Women's Health Study $(1997-2010)^{*}$

\begin{tabular}{|c|c|c|c|c|}
\hline & \multicolumn{2}{|l|}{ Men } & \multicolumn{2}{|l|}{ Women } \\
\hline & No type 2 diabetes & Type 2 diabetes & No type 2 diabetes & Type 2 diabetes \\
\hline Number of participants & 55311 & 4599 & 66823 & 6291 \\
\hline Age at baseline $(y)$ & 54.89 (9.63) & $60.48(9.61)$ & $51.94(8.91)$ & $58.51(8.34)$ \\
\hline \multicolumn{5}{|l|}{ Education level (\%) } \\
\hline Illiteracy or elementary school & 6.27 & 11.33 & 19.28 & 43.18 \\
\hline Middle school & 33.51 & 33.57 & 37.95 & 29.27 \\
\hline High school & 36.69 & 29.53 & 28.85 & 18.41 \\
\hline Graduate school/college & 23.52 & 25.57 & 13.92 & 9.14 \\
\hline \multicolumn{5}{|l|}{ Income $(\%) \dagger$} \\
\hline Low & 12.86 & 9.24 & 15.58 & 21.43 \\
\hline Low-middle & 77.45 & 80.82 & 38.08 & 39.88 \\
\hline Middle-high & 8.93 & 9.26 & 28.47 & 24.34 \\
\hline High & 0.76 & 0.68 & 17.87 & 14.35 \\
\hline \multicolumn{5}{|l|}{ Occupation (\%) } \\
\hline Housewife & - & - & 0.34 & 0.64 \\
\hline Professional & 25.79 & 31.92 & 29.98 & 22.78 \\
\hline Clerical & 21.92 & 22.53 & 20.81 & 20.32 \\
\hline Manual worker & 52.29 & 45.55 & 49.87 & 56.26 \\
\hline BMI $\left(\mathrm{kg} / \mathrm{m}^{2}\right)$ & $23.64(3.07)$ & $24.61(3.04)$ & $23.82(3.33)$ & $26.00(3.76)$ \\
\hline \multicolumn{5}{|l|}{ BMI (\%) } \\
\hline Less than 18.5 & 4.49 & 1.48 & 3.58 & 1.30 \\
\hline $18.5-24.0$ & 50.79 & 43.23 & 51.82 & 29.08 \\
\hline $24.0-28.0$ & 37.01 & 41.47 & 33.83 & 42.39 \\
\hline Greater than 28 & 7.71 & 13.83 & 10.77 & 27.23 \\
\hline \multicolumn{5}{|l|}{ Smoking status (\%) } \\
\hline Never smokers & 29.69 & 38.16 & 97.47 & 95.25 \\
\hline Former smokers & 10.29 & 17.33 & & \\
\hline Current smokers & 60.02 & 44.51 & $2.59 \ddagger$ & $4.75 \ddagger$ \\
\hline Physical activity (MET h/week) & $59.56(34.03)$ & $61.04(35.83)$ & $107.00(45.30)$ & $102.50(43.31)$ \\
\hline Ever alcohol intake (\%) & 34.82 & 29.03 & 2.29 & 1.87 \\
\hline Total energy intake (kcal/day) & $8029.80(2029.10)$ & $7481.00(1929.50)$ & $7033.90(1681.10)$ & $6845.10(1842.40)$ \\
\hline Fruit intake (g/day) & $155.10(125.00)$ & $98.58(110.50)$ & $271.90(178.30)$ & $187.90(175.30)$ \\
\hline Vegetable intake (g/day) & 341.20 (190.10) & $373.20(218.40)$ & $295.70(168.70)$ & 305.70 (188.70) \\
\hline Family history of cancer (\%) & 28.27 & 30.03 & 26.48 & 26.61 \\
\hline Postmenopausal (\%) & - & - & 46.27 & 76.58 \\
\hline HRT use (\%) & - & - & 2.07 & 2.10 \\
\hline
\end{tabular}

${ }^{*}$ Continuous variables are presented as the mean (the SD).

†Low: less than $¥ 10000$ per family per year for women and less than $¥ 1000$ per person per month for men; low to middle: $¥ 10000-19999$ per family per year for women and $¥ 1000-3000$ per person per month for men; middle to high: $¥ 20000-29999$ per family per year for women and $¥ 3000-5000$ per person per month for men; high: greater than $¥ 30000$ per family per year for women and more than $¥ 5000$ per person per month for men.

fOwing to the small number of smokers among women, the number of current and former smokers was combined.

$\mathrm{BMI}$, body mass index; DM, diabetes mellitus; HRT, hormone replacement therapy; MET, metabolic equivalents ( $1 \mathrm{MET} h=15$ min of moderate intensity activity).

association have not adjusted for $\mathrm{BMI}^{16}$ or smoking; ${ }^{32}$ two studies ${ }^{25}{ }^{26}$ with a null association used case-control design; three studies have a limited follow-up period $(<5 \text { years })^{1121}$ or sample size $(<10000) .{ }^{15}$ Consistent with most pertinent studies, ${ }^{17} 19-222433-35$ we observed a null association between T2D and lung cancer risk overall and among non-smoking participants.

Although a null association was found between T2D and lung cancer, previous observational studies have consistently shown the increased risk of several incident cancers among individuals with T2D, including cancers of the liver ${ }^{5}{ }^{6}$ and pancreas. ${ }^{7}$ The potential biological links between diabetes and cancer risk included hyperinsulinaemia (either endogenous due to insulin resistance or exogenous due to administered insulin or insulin secretogogues), hyperglycaemia and/or chronic inflammation. ${ }^{36}$ The hyperinsulinaemia may involve in carcinogenesis by its mitogenic effect via the insulin/insulin-like growth factor axis. ${ }^{36}$ On the other hand, hyperglycaemia may cause an abnormal energy balance and impair the effect of ascorbic acid on the intracellular metabolism and reduce the effectiveness of the immune system, ${ }^{37}$ which could favour cancer incidence and progression in diabetic patients. In addition, free fatty acids, interleukin 
Table 2 HRs for the association between type 2 diabetes and lung cancer risk in the Shanghai Men's Health Study (2002-2010) and the Shanghai Women's Health Study (1997-2010)

\begin{tabular}{|c|c|c|c|c|c|}
\hline & \multicolumn{2}{|l|}{ No type 2 diabetes } & \multicolumn{3}{|l|}{ Type 2 diabetes } \\
\hline & $\begin{array}{l}\text { Number of cases/ } \\
\text { person-years }\end{array}$ & HR $(95 \% \mathrm{Cl})$ & $\begin{array}{l}\text { Number of cases/ } \\
\text { person-years }\end{array}$ & $\begin{array}{l}\text { Age-adjusted } \\
\mathrm{HR}(95 \% \mathrm{Cl})\end{array}$ & $\begin{array}{l}\text { Multivariable-adjusted } \\
\text { HR }(95 \% \mathrm{Cl})^{\star}\end{array}$ \\
\hline \multicolumn{6}{|l|}{ Men } \\
\hline Entire cohort & 450/354 902 & 1.00 (referent) & $42 / 28825$ & 0.80 (0.58 to 1.10$)$ & $0.87(0.62$ to 1.21$)$ \\
\hline $\begin{array}{l}\text { Sensitivity } \\
\text { analysis } \dagger\end{array}$ & $260 / 354604$ & 1.00 (referent) & $28 / 28805$ & 0.94 (0.64 to 1.39$)$ & $1.10(0.73$ to 1.64$)$ \\
\hline \multicolumn{6}{|l|}{ Women } \\
\hline Entire cohort & $469 / 801158$ & 1.00 (referent) & $56 / 72600$ & $0.88(0.66$ to 1.18$)$ & $0.93(0.69$ to 1.25$)$ \\
\hline $\begin{array}{l}\text { Sensitivity } \\
\text { analysis† }\end{array}$ & $396 / 801041$ & 1.00 (referent) & $52 / 72596$ & 0.93 (0.69 to 1.26$)$ & 0.99 (0.72 to 1.34$)$ \\
\hline
\end{tabular}

Table 3 HRs for the association between type 2 diabetes and lung cancer risk, stratified by waist-to-hip ratio, waist circumference, smoking and menopausal status (women) in the Shanghai Men's Health Study (2002-2010) and the Shanghai Women's Health Study (1997-2010)*

\begin{tabular}{|c|c|c|c|c|}
\hline & \multicolumn{2}{|l|}{ No type 2 diabetes } & \multicolumn{2}{|l|}{ Type 2 diabetes } \\
\hline & $\begin{array}{l}\text { Number of cases/ } \\
\text { person-years }\end{array}$ & HR (95\% Cl) & $\begin{array}{l}\text { Number of cases/ } \\
\text { person-years }\end{array}$ & HR $(95 \% \mathrm{Cl})^{*}$ \\
\hline \multicolumn{5}{|l|}{ Men } \\
\hline \multicolumn{5}{|l|}{ Waist-to-hip ratio† } \\
\hline 1st tertile & $187 / 122101$ & 1.00 (referent) & $7 / 5808$ & $0.59(0.27$ to 1.28$)$ \\
\hline 2nd tertile & $129 / 121267$ & 1.00 (referent) & $10 / 9063$ & $0.67(0.35$ to 1.30$)$ \\
\hline 3rd tertile & $134 / 111533$ & 1.00 (referent) & $25 / 13954$ & $1.13(0.71$ to 1.78$)$ \\
\hline \multicolumn{5}{|l|}{ Waist circumference $(\mathrm{cm}) \ddagger$} \\
\hline Less than 85 & $163 / 93856$ & 1.00 (referent) & $4 / 4254$ & $0.38(0.14$ to 1.04$)$ \\
\hline Greater than 85 & $287 / 261046$ & 1.00 (referent) & $38 / 24571$ & $1.02(0.71$ to 1.46$)$ \\
\hline \multicolumn{5}{|l|}{ Smoking status } \\
\hline Never smoker & $53 / 106860$ & 1.00 (referent) & $10 / 11199$ & $1.46(0.71$ to 3.02$)$ \\
\hline Former smoker & $76 / 36466$ & 1.00 (referent) & $13 / 4811$ & $0.97(0.52$ to 1.80$)$ \\
\hline Current smoker & $321 / 211575$ & 1.00 (referent) & $19 / 12815$ & $0.67(0.41$ to 1.10$)$ \\
\hline \multicolumn{5}{|l|}{ Smoking (pack-years) } \\
\hline $0-10$ & $80 / 147829$ & 1.00 (referent) & $11 / 14143$ & $1.06(0.54$ to 2.06$)$ \\
\hline $10-20$ & $55 / 70068$ & 1.00 (referent) & $5 / 4313$ & 0.93 (0.36 to 2.42$)$ \\
\hline Greater than 20 & $315 / 137004$ & 1.00 (referent) & $26 / 10369$ & $0.78(0.51$ to 1.19$)$ \\
\hline \multicolumn{5}{|l|}{ Women } \\
\hline \multicolumn{5}{|l|}{ Waist-to-hip ratiof } \\
\hline 1st tertile & $133 / 282622$ & 1.00 (referent) & 2/8367 & $0.44(0.11$ to 1.80$)$ \\
\hline 2nd tertile & $139 / 277675$ & 1.00 (referent) & $24 / 20108$ & $1.37(0.80$ to 2.34$)$ \\
\hline 3rd tertile & $197 / 240861$ & 1.00 (referent) & $30 / 44126$ & $0.63(0.40$ to 1.01$)$ \\
\hline \multicolumn{5}{|l|}{ Waist circumference $(\mathrm{cm}) \S$} \\
\hline Less than 80 & $245 / 502838$ & 1.00 (referent) & $15 / 20482$ & $1.01(0.56$ to 1.82$)$ \\
\hline More than 80 & $224 / 298320$ & 1.00 (referent) & $41 / 52119$ & $0.74(0.49$ to 1.13$)$ \\
\hline \multicolumn{5}{|l|}{ Smoking status ${ }^{\star \star}$} \\
\hline Never smoker & $428 / 781407$ & 1.00 (referent) & $50 / 69261$ & $0.98(0.72$ to 1.34$)$ \\
\hline Former and current smoker & $41 / 19751$ & 1.00 (referent) & $6 / 3339$ & $0.53(0.21$ to 1.39$)$ \\
\hline \multicolumn{5}{|l|}{ Menopausal status } \\
\hline Yes & $365 / 365579$ & 1.00 (referent) & $49 / 54772$ & $0.84(0.61$ to 1.50$)$ \\
\hline No & $104 / 435575$ & 1.00 (referent) & $7 / 17828$ & $2.12(0.96$ to 4.67$)$ \\
\hline $\begin{array}{l}{ }^{*} \text { The adjusted covariates are as indi } \\
\dagger 1 \text { st tertile: }<0.878 ; 2 \text { nd tertile: } 0.878 \\
\ddagger A \text { waist circumference } \geq 85 \mathrm{~cm} \text { for } m \\
\text { П1 st tertile: }<0.785 ; 2 \text {; tertile: } 0.78 \\
\S A \text { waist circumference } \geq 80 \mathrm{~cm} \text { for } \\
\S{ }^{* \star} \text { Owing to the limited number of for }\end{array}$ & $\begin{array}{l}\text { in table } 1 . \\
\text { 4; 3rd tertile: } \geq 0.924 \text {. } \\
\text { Is defined as overweigr } \\
1 ; \text { 3rd tertile: } \geq 0.831 \text {. } \\
\text { inas defined as overw }\end{array}$ & $\begin{array}{l}\text { central adiposit } \\
\text { and central adip }\end{array}$ & 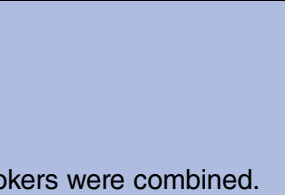 & \\
\hline
\end{tabular}


6 , monocyte chemoattractant protein, plasminogen activator inhibitor 1, adiponectin, leptin and tumour necrosis factor $\alpha$, which were produced by adipose tissue among T2D-related obesity, may play an aetiological role in regulating malignant transformation or cancer progression. $^{36}$

The strengths of our study include the populationbased cohort design, large sample size, high response rates of follow-ups (over $96 \%$ for in-person home visits) and the use of repeated measures of diabetes status. However, several limitations to this study should be noted. As cases of diabetes were self-reported and a number of patients with diabetes did not know they had the disease ${ }^{38}$ the misclassification of T2D cannot be ruled out and could be non-differential, thus leading to the underestimation of the true association. Nevertheless, we observed a high agreement between self-reported data and data from medical records and laboratory tests for T2D in a random sample of participants from our cohorts. Also, previous validation studies ${ }^{39} 40$ indicated that a self-reported history of diabetes could be reasonably accurate and could provide a useful assessment for broad measures of diabetes in the large-scale observational study.

In addition, the findings from SWHS would have been affected by the over-detection bias, given the higher incidence rate of lung cancer in the first year following the diabetes index date compared with those without diabetes, regardless of the different time intervals of follow-up. However, the results were unchanged in the analysis after excluding lung cancer cases occurring within the first 3 years after diabetes onset. Moreover, this potentially increased ascertainment in diabetics is unlikely to occur in SMHS because of the lower incidence rate of lung cancer in the diabetic cohort within the first year after the diabetes diagnosis.

Other limitations to the study include the lack of pharmacological data on diabetes treatments, including hypoglycaemic agent use and degree of glucose control. However, sensitivity analysis showed a similarly null association between untreated diabetes and risk of lung cancer, indicating that the diabetes treatments may not affect our main results. This finding should be interpreted with caution because information for the history of hypoglycaemic drug use was based on self-reported data in our study.

In summary, our cohort study indicated that T2D is not associated with lung cancer risk. Future research to find other modifiable risk factors for lung cancer should be warranted.

\footnotetext{
Author affiliations

${ }^{1}$ Department of Epidemiology, Shanghai Cancer Institute, Renji Hospital, Shanghai Jiaotong University School of Medicine, Shanghai, China

${ }^{2}$ State Key Laboratory of Oncogene and Related Genes, Shanghai Cancer Institute, Renji Hospital, Shanghai Jiaotong University School of Medicine, Shanghai, China

${ }^{3}$ Department of Social Science and Public Health, School of Basic Medical Science, Jiujiang University, Jiujiang, China
}

${ }^{4}$ Division of Epidemiology, Department of Medicine, Vanderbilt Epidemiology Center, Vanderbilt-Ingram Cancer Center, Vanderbilt University School of Medicine, Nashville, Tennessee, USA

${ }^{5}$ Division of Cancer Prevention and Population Sciences, Department of Epidemiology, University of Texas MD Anderson Cancer Center, Houston, Texas, USA

${ }^{6}$ Division of Cancer Epidemiology and Genetics, National Cancer Institute, Rockville, Maryland, USA

Acknowledgements The authors would like to thank the participants of the Shanghai Men's Health Study and the Shanghai Women's Health Study for the invaluable contribution to this work.

Contributors $Y-B X$ contributed to the conception and design of the study; Y-BX, H-LL and Y-TG acquired the data; W-SY, YY and Y-BX performed the statistical analysis and the interpretation of results; W-SY wrote the first draft. All authors contributed to the critical review of the manuscript and approved the final manuscript; Y-BX had full access to all of the data and had the final responsibility for the decision to submit for publication.

Funding This work was supported by the US National Institutes of Health (grant number R37 CA070867 and R01 CA82729); the fund of Key Discipline and Specialty Foundation of Shanghai Municipal Commission of Health and Family Planning.

\section{Competing interests None.}

Ethics approval Institutional review boards (IRBs) of Vanderbilt University (USA) and Shanghai Cancer Institute (China).

Provenance and peer review Not commissioned; internally peer reviewed.

Data sharing statement No additional data are available.

Open Access This is an Open Access article distributed in accordance with the Creative Commons Attribution Non Commercial (CC BY-NC 3.0) license, which permits others to distribute, remix, adapt, build upon this work noncommercially, and license their derivative works on different terms, provided the original work is properly cited and the use is non-commercial. See: http:// creativecommons.org/licenses/by-nc/3.0/

\section{REFERENCES}

1. Jemal A, Bray F, Center MM, et al. Global cancer statistics. CA Cancer J Clin 2011;61:69-90.

2. Pan XR, Yang WY, Li GW, et al. Prevalence of diabetes and its risk factors in China, 1994. National Diabetes Prevention and Control Cooperative Group. Diabetes Care 1997;20:1664-9.

3. Yang W, Lu J, Weng J, et al. Prevalence of diabetes among men and women in China. N Engl J Med 2010;362:1090-101.

4. Hu FB. Globalization of diabetes: the role of diet, lifestyle, and genes. Diabetes Care 2011;34:1249-57

5. Yang WS, Shu XO, Gao J, et al. Prospective evaluation of type 2 diabetes mellitus on the risk of primary liver cancer in Chinese men and women. Ann Oncol 2013;24:1679-85.

6. Yang WS, Va P, Bray F, et al. The role of pre-existing diabetes mellitus on hepatocellular carcinoma occurrence and prognosis: a meta-analysis of prospective cohort studies. PLOS ONE 2011;6: e27326.

7. Ben $\mathrm{Q}, \mathrm{Xu} \mathrm{M}, \mathrm{Ning} \mathrm{X}$, et al. Diabetes mellitus and risk of pancreatic cancer: a meta-analysis of cohort studies. Eur J Cancer 2011;47:1928-37.

8. Armstrong B, Lea AJ, Adelstein AM, et al. Cancer mortality and saccharin consumption in diabetics. Br J Prev Soc Med 1976;30:151-7.

9. Atchison EA, Gridley G, Carreon JD, et al. Risk of cancer in a large cohort of U.S. veterans with diabetes. Int $J$ Cancer 2011;128:635-43.

10. Lo SF, Chang SN, Muo $\mathrm{CH}$, et al. Modest increase in risk of specific types of cancer types in type 2 diabetes mellitus patients. Int J Cancer 2013;132:182-8.

11. Ogunleye AA, Ogston SA, Morris AD, et al. A cohort study of the risk of cancer associated with type 2 diabetes. $\mathrm{Br} J$ Cancer 2009;101:1199-201.

12. Seshasai SR, Kaptoge S, Thompson A, et al. Emerging Risk Factors C. Diabetes mellitus, fasting glucose, and risk of cause-specific death. N Engl J Med 2011;364:829-41. 
13. Kuriki K, Hirose K, Tajima K. Diabetes and cancer risk for all and specific sites among Japanese men and women. Eur J Cancer Prev 2007; 16:83-9.

14. Carstensen B, Witte DR, Friis S. Cancer occurrence in Danish diabetic patients: duration and insulin effects. Diabetologia 2012;55:948-58.

15. Luo J, Chlebowski R, Wactawski-Wende J, et al. Diabetes and lung cancer among postmenopausal women. Diabetes Care 2012;35:1485-91.

16. Jee $\mathrm{SH}$, Ohrr $\mathrm{H}$, Sull JW, et al. Fasting serum glucose level and cancer risk in Korean men and women. JAMA 2005;293:194-202.

17. Coughlin SS, Calle EE, Teras LR, et al. Diabetes mellitus as a predictor of cancer mortality in a large cohort of US adults. Am J Epidemiol 2004;159:1160-7.

18. Saydah SH, Loria CM, Eberhardt MS, et al. Abnormal glucose tolerance and the risk of cancer death in the United States. Am J Epidemiol 2003;157:1092-100.

19. Inoue M, Iwasaki M, Otani T, et al. Diabetes mellitus and the risk of cancer: results from a large-scale population-based cohort study in Japan. Arch Intern Med 2006;166:1871-7.

20. Steenland K, Nowlin S, Palu S. Cancer incidence in the Nationa Health and Nutrition Survey I. Follow-up data: diabetes, cholesterol, pulse and physical activity. Cancer Epidemiol Biomarkers Prev 1995:4:807-11.

21. Hall GC, Roberts CM, Boulis M, et al. Diabetes and the risk of lung cancer. Diabetes Care 2005;28:590-4.

22. Khan M, Mori M, Fujino $Y$, et al. Site-specific cancer risk due to diabetes mellitus history: evidence from the Japan Collaborative Cohort (JACC) study. Asian Pac J Cancer Prev 2006;7:253-9.

23. Rapp K, Schroeder J, Klenk J, et al. Fasting blood glucose and cancer risk in a cohort of more than 140,000 adults in Austria. Diabetologia 2006;49:945-52.

24. Stattin $\mathrm{P}$, Bjor $\mathrm{O}$, Ferrari $\mathrm{P}$, et al. Prospective study of hyperglycemia and cancer risk. Diabetes Care 2007;30:561-7.

25. Rousseau MC, Parent ME, Pollak MN, et al. Diabetes mellitus and cancer risk in a population-based case-control study among men from Montreal, Canada. Int J Cancer 2006;118:2105-9.

26. O'Mara BA, Byers T, Schoenfeld E. Diabetes mellitus and cancer risk: a multisite case-control study. J Chronic Dis 1985;38:435-41.

27. Villegas R, Yang G, Liu D, et al. Validity and reproducibility of the food-frequency questionnaire used in the Shanghai men's health study. Br J Nutr 2007;97:993-1000.
28. Zheng W, Chow WH, Yang G, et al. The Shanghai Women's Health Study: rationale, study design, and baseline characteristics. Am J Epidemiol 2005;162:1123-31.

29. Zhou BF, Cooperative Meta-Analysis Group of the Working Group on Obesity in $\mathrm{C}$. Predictive values of body mass index and wais circumference for risk factors of certain related diseases in Chinese adults-study on optimal cut-off points of body mass index and waist circumference in Chinese adults. Biomed Environ Sci 2002;15:83-96.

30. Ainsworth BE, Haskell WL, Whitt MC, et al. Compendium of physica activities: an update of activity codes and MET intensities.

Med Sci Sports Exerc 2000;32(9 Suppl):S498-504.

31. Ainsworth BE, Haskell WL, Leon AS, et al. Compendium of physical activities: classification of energy costs of human physical activities. Med Sci Sports Exerc 1993;25:71-80.

32. Chodick G, Heymann AD, Rosenmann L, et al. Diabetes and risk of incident cancer: a large population-based cohort study in Israel. Cancer Causes Control 2010;21:879-87.

33. Ehrlich SF, Quesenberry CP Jr, Van Den Eeden SK, et al. Patients diagnosed with diabetes are at increased risk for asthma, chronic obstructive pulmonary disease, pulmonary fibrosis, and pneumonia but not lung cancer. Diabetes Care 2010;33:55-60.

34. Wotton CJ, Yeates DG, Goldacre MJ. Cancer in patients admitted to hospital with diabetes mellitus aged 30 years and over: record linkage studies. Diabetologia 2011;54:527-34.

35. Yeh HC, Platz EA, Wang NY, et al. A prospective study of the associations between treated diabetes and cancer outcomes. Diabetes Care 2012;35:113-18.

36. Giovannucci E, Harlan DM, Archer MC, et al. Diabetes and cancer: a consensus report. Diabetes Care 2010;33:1674-85

37. Vigneri P, Frasca F, Sciacca L, et al. Diabetes and cancer. Endocr Relat Cancer 2009;16:1103-23.

38. Li R, Lu W, Jiang QW, et al. Increasing prevalence of type 2 diabetes in Chinese adults in Shanghai. Diabetes Care 2012;35:1028-30.

39. Martin LM, Leff M, Calonge $\mathrm{N}$, et al. Validation of self-reported chronic conditions and health services in a managed care population. Am J Prev Med 2000;18:215-18.

40. Wu SC, Li CY, Ke DS. The agreement between self-reporting and clinical diagnosis for selected medical conditions among the elderly in Taiwan. Public Health 2000;114:137-42. 